\title{
Study on the Influence of Physical and Mental Health of Colleges Students under the Asynchronous Teaching Mode
}

\author{
Yuwang ZHANG \\ China University of Geosciences(BEI JING) Physical Education department
}

\begin{abstract}
Combined with the theory of asynchronous teaching method, this research mainly adopted expert interviews, teaching experiment, mathematical statistics. Asynchronous teaching experiment of our school students which were in physical fitness classes was done. The teaching procedure and the evaluation method were studied and designed, the teaching process was controlled. The results showed that: the asynchronous teaching mode can improve physical fitness classes students' mental health level. Compared with the traditional teaching method, asynchronous teaching can effectively develop students' speed, strength, endurance, agility, coordination of physical ability. The students in the experimental class are significant or very significant difference in 100 meters, sit ups, step index, body anteflexion in sitting position, 4 x 10 meters from the run, standing long jump and reaction time. At the same time the asynchronous teaching mode can promote students' mental health and alleviate their psychological pressure, the experimental class students are significantly or very significantly difference in anxiety, somatization, compulsion, interpersonal, paranoid ideation. They are also significantly or very significantly difference in health pressure, adapting pressure, inferior to frustration stress, interpersonal stress, academic pressure, emotional pressure and other indicators.

KEYWORD: asynchronous teaching method; Physical fitness; mental health; pressure; difference
\end{abstract}

\section{INTRODUCTION}

Ministry of Education, State Sport General Administration, Communist Youth League Central Committee jointly launched nationwide "sunshine sports" for millions of students in 2007, which is of great historical and realistic significance and physical education in schools has been strengthened and emphasized. However, State Sport General Administration, Ministry of Education releases 2010 National physique monitoring result on September 2, 2011; it shows that compared to 2005 data, Chinese college students in their 19-22 age have a further decline in physical fitness, strength, endurance, although the drop compared with the previous 5 years (2000-2005) is significantly reduced, but still with gaps in accordance with the "5 year index" in document 7 of central government. College students physical ability is generally poor when entering university. In order to improve the effectiveness of Sunshine sports and improve student's physical condition, our university offers physical curriculum for all students in order to improve their strength, flexibility, strength and endurance. The author found in teaching that currently sports teaching although is classified as different classes by sports level and interest however, body shape, and sports base, and skills level is dfferent. Teaching method, teaching requirements and the evaluation standard cannot vary from person to person, in some degree, will affect sports teaching quality which cannot improve students' learning interest, thus student learning pressure is generally larger. In response to this situation, in order to achieve individualized student learning, giving full play to the enthusiasm of students and teachers ' leading role, based on asynchronous teaching to explore effective solutions for the learning differences.

\section{RESEARCH METHODS}

\subsection{Documentation:}

The author read a lot of related literatures on education, sports pedagogy, sports psychology and system theory, asynchronous teaching and so on, which explores the basis for the feasibility of asynchronous teaching and experimental implementation. 


\subsection{Expert interviews}

The author has visited many experts and scholars of well-known colleges like Beijing University of physical education, capital Institute of physical education, Tsinghua University, Peking University, Beijing Normal University and consultation has been conducted for the asynchronous teaching method in physical education to explore practical steps.

\subsection{Teaching experimentation}

Four girls in our university out of 130 students were randomly selected to conduct fitness experiment in 2012-2013, 2 classes are regarded as the experimental class, 64 students included; 2 classes are regarded as comparison class, 66 students included. Asynchronous teaching was conducted in experimental class for one semester. Comparison class was taught in a traditional way. Course content includes: single exercise and group exercises of every physique, 2 hours per week, 16 weeks in total , i.e.,32 hours. Experimental and control groups are exactly the same on teaching conditions, equipment, schedule, number of teaching hours, course content . Experimental time is from September to December in 2012. Indicators of physical and mental health for all students were compared.

In the experimental class, asynchronous teaching was divided into classroom asynchronous procedure of teacher and classroom guidance program.

The first step is to understand and students ' learning sports ability and interest in hobbies, sports motivation, students were separated into different groups, and the overall objectives of physical education curriculum for each group was established in relevant criteria.

The second step, teaching all students in every lesson, explaining the techniques. Next, provide background, setting question, inspiring students to practice thinking and stimulate students ' interest in and desire ;the teaching objectives are to stimulate students ' interest in learning and practicing. In the course of another practicing, teachers should correct mistakes students made in practice timely, give specific guidance for the questions student ask. Teachers organize and supervise throughout the process, give guidance and correction for the students on the common problems that appear at any time.

\subsection{Physical test methods}

The initial level test was conducted in experiment classes and control classes prior to the test, T-test of the test data was conducted to determine the rationality of experiment group.
Physical fitness test was conducted after the second fitness test, T-test of the test data is implemented to determine the fitness level of experimental classes and control classes to determine if there is a difference.

\subsection{Mental health and stress testing}

This article uses SCL-90 mental health symptom self-rating scale and "psychological stress scale for college students" prepared by Zhang Lin, Wen Bo, Li Bing, et al.. The SCL-90 contains the body, obsessive-compulsive symptom, interpersonal sensitivity, depression, anxiety, hostility, fear, paranoia, psychosis and others (such as sleeping and eating, et al.). Higher scores indicates lower mental health level. The psychological stress scale for college students, made up of 62 topics, the psychological pressure of college students is divided into 11 dimensions including family pressure, health stress,adaption stress, love stress, low self-esteem, interpersonal stress, emotional stress and job stress . Two scales have been widely used at home and abroad, evaluation results have a high reliability and validity, accurately describe the participants subjective symptoms, et al. features.

Before the study, classes and control classes students mental health tests, to determine whether their initial level of mental health are different. Experimental classes and control classes after students ' psychological health and mental stress test to determine whether an asynchronous teaching mode on its impact.

\subsection{Mathematical statistics}

All data in average $(\mathrm{x}) \pm$ the standard deviation ( $\mathrm{s}$ ) output, t-test and analysis using SPSS13.0 software discussions.

\section{EXPERIMENTAL RESULTS AND ANALYSIS}

3.1 The beginning of the semester classes and control classes the physical indicators and indicators of mental health test results and analysis

Beginning of the semester, students ' classes and control classes tested 6 indicators of physical and mental health, the test results for the t-test (see tables 1 and 2), the results show that students in four quality no significant differences in levels of physical and mental health, and statistically that the group meet experimental requirements, four classes of initial level. 
Table 1 Classes and control classes the students at the beginning of the semester each physical index testing

Groups 50 meters standing long jump of the vital capacity indexes of sit-ups medicine ball 800 meter
(s) $\quad(\mathrm{cm})$
(次/分)
(m)
( $\mathrm{s}$ )

$\mathrm{X} \pm \mathrm{S} \mathrm{X} \pm \mathrm{S} \mathrm{X} \pm \mathrm{S} \mathrm{X} \pm \mathrm{S} \mathrm{X} \pm \mathrm{S} \mathrm{X} \pm \mathrm{S}$

Science experiments (64) $1.76 \pm 0.61 \pm 241759.249 .34 \pm 32 \pm 4.65 .3 \pm 2.14252 \pm 32$

Control classes (66) $9.35 \pm 0.57 \pm 201749.41 \pm 1.44 \pm 3.95 .2 \pm 2.28249 \pm 3341$

T-test 1.06160 .05101 .33500 .4658

P P $(0.2$ P $(0.2$ P $(0.2 \mathrm{P}(0.5 \mathrm{P}(0.2 \mathrm{P}(0.2$

Table 2 semester classes and control classes SCL-90 scale factor measurement mean value test

\begin{tabular}{|c|c|c|c|c|}
\hline Factor values & The experimental class & The control class & $\mathrm{T}$ & $\mathrm{P}$ \\
\hline Somatization & $1.41 \pm 0.26$ & $1.39 \pm 0.28$ & 0.4222 & $\mathrm{P}(0.2$ \\
Obsessive-compu & $1.46 \pm 0.24$ & $1.47 \pm 0.29$ & 0.2145 & $\mathrm{P}(0.2$ \\
lsive symptoms & $1.51 \pm 0.39$ & $1.54 \pm 0.32$ & 0.4787 & $\mathrm{P}(0.2$ \\
Interpersonal sensitivity & $1.34 \pm 0.43$ & $1.33 \pm 0.41$ & 0.1356 & $\mathrm{P}(0.2$ \\
Depression & $1.28 \pm 0.31$ & $1.31 \pm 0.30$ & 1.1049 & $\mathrm{P}(0.2$ \\
Anxiety & $1.41 \pm 0.34$ & $1.42 \pm 0.35$ & 0.1652 & $\mathrm{P}(0.2$ \\
Hostile & $1.20 \pm 0.31$ & $1.18 \pm 0.34$ & 0.3507 & $\mathrm{P}(0.2$ \\
Terror & $1.39 \pm 0.23$ & $1.38 \pm 0.24$ & 0.2426 & $\mathrm{P}(0.2$ \\
Paranoia & $1.13 \pm 0.25$ & $1.14 \pm 0.29$ & 0.2107 & $\mathrm{P}(0.2$ \\
Psychotic & $1.23 \pm 0.26$ & $1.28 \pm 0.34$ & 0.9436 & $\mathrm{P}(0.2$ \\
Other & & & \\
\hline
\end{tabular}

Table 3 test classes and control classes after 9 students physical fitness index difference test

\begin{tabular}{|c|c|c|c|c|}
\hline Index & The experimental class & The control class & $\mathrm{T}$ value & $\mathrm{P}$ \\
\hline 100 meter $(\mathrm{s})$ & $14.54 \pm 0.53$ & $15.02 \pm 0.86$ & 3.8436 & $\mathrm{P}<0.01$ \\
\hline Sit-ups (times/min) & $42.21 \pm 4.13$ & Microsoft Bing Translation Error & 2.6773 & $\mathrm{P}<0.01$ \\
\hline Medicine balls (m) & $6.43 \pm 2.28$ & $5.91 \pm 2.09$ & 1.3543 & $\mathrm{P}(0.2$ \\
\hline Step index & $74.55 \pm 4.23$ & $70.53 \pm 4.99$ & 4.9601 & $\mathrm{P}<0.01$ \\
\hline Reaction time (s) & $0.443 \pm 0.021$ & $0.449 \pm 0.019$ & 1.7066 & $\mathrm{P}<0.05$ \\
\hline Soft riding standing on one foot with eyes closed (s) & $5.36 \pm 2.15$ & $5.29 \pm 2.06$ & 0.1894 & $\mathrm{P}(0.2$ \\
\hline
\end{tabular}

Table 4 test classes and control classes SCL-90 scale after evaluating each factor values test

\begin{tabular}{|c|c|c|c|c|}
\hline Factor values & The experimental class & The control class & $\mathrm{T}$ & $\mathrm{P}$ \\
\hline Somatization & $1.22 \pm 0.18$ & Microsoft Bing Translation Error & 2.3344 & $\mathrm{P}<0.05$ \\
Obsessive-compulsive & $1.33 \pm 0.17$ & Microsoft Bing Translation Error & 1.6949 & $\mathrm{P}<0.05$ \\
symptoms & $1.32 \pm 0.22$ & $1.40 \pm 0.25$ & 1.9384 & $\mathrm{P}<0.05$ \\
Interpersonal sensitivity & $1.20 \pm 0.26$ & $1.25 \pm 0.31$ & 0.9975 & $\mathrm{P}(0.2$ \\
Depression & $1.13 \pm 0.19$ & $1.22 \pm 0.19$ & 2.7000 & $\mathrm{P}<0.01$ \\
Anxiety & $1.32 \pm 0.34$ & $1.37 \pm 0.35$ & 0.1838 & $\mathrm{P}(0.2$ \\
Hostile & $1.18 \pm 0.30$ & $1.17 \pm 0.32$ & 2.3452 & $\mathrm{P}(0.2$ \\
Terror & $1.23 \pm 0.16$ & $1.30 \pm 0.18$ & 0.2375 & $\mathrm{P}<0.05$ \\
Paranoia & $1.11 \pm 0.23$ & $1.12 \pm 0.25$ & 0.6924 & $\mathrm{P}(0.2$ \\
Psychotic & $1.21 \pm 0.21$ & $1.24 \pm 0.28$ & \\
Other & & & &
\end{tabular}

3.2 Asynchronous teaching to the students of the physical and psychological impact of indicators and statistical tests on various groups of indicators

Currently in class teaching under the condition of school physical education in China, according to the students ' physical aptitude is more difficult to control the situation. And asynchronous teaching in school teaching of total target not variable of premise
Xia, can according to students different of learning accept capacity and other of some related factors will students into several different level of teaching group, and according to different teaching group in students of reality selection and of phase match sports teaching method, and content, and means and evaluation method, makes each students are can in teachers of guide and help Xia active to efforts learning completed and of phase adapted of teaching target. 
3.2.1 Experimental analysis on the comparison of different indicators of physical fitness classes and control classes after

Fitness level mainly reflects the student's strength, speed, flexibility, agility, coordination, and balance, et al. basic motor skills. To test asynchronous experiment teaching semester of classes and control classes students 9 indicators of physical fitness tests. Testing quality indicators for $100 \mathrm{~m}$, strength quality index for sit-ups, standing long jump and medicine balls, index of endurance step test, bending flexible quality indicators used seat, sensitivity indices for $4 \times 10 \mathrm{~m}$ shuttle run, coordination is applied to reaction time, balance indicator uses soft riding standing on one foot with eyes closed. Test results and test are shown in table 3.

As can be seen from table 3 , the students of the asynchronous teaching steps after 16 weeks of teaching, and in the various physical indicators have varying degrees of growth. Due to asynchronous teaching in class Shang to students for learning of master, and teachers for learning led who, will teachers of individual guide, and classification Guide and all guide, et al. three species guide form and students of group learning and alone learning organic to unified in a teaching process in the, teaching in the according to students different levels of learning level, on each teaching Group respectively design has different levels of practice content and method, and learning who level phase adapted of class teaching evaluation system. Every student in the specific objectives under the guidance of, and gradually achieve this goal. Therefore, asynchronous teaching can improve the technical level of sports. The traditional teaching methods tend to ignore the initiative of students and students ' personality development, unified explanation, unified demonstration of teachers, standard examination, students learning by rote and practice, this "one size fits all" teaching mode in the negative impact on the teaching effect to some extent. In 9 items physical indicators in the, and control class compared, class students 100 meters, and sit-ups, and steps index, and seat body Qian flexor, and 4x10 meters roundtrip ran, et al. 5 items indicators statistics test has very significantly sex differences, in standing long jump and reaction Shi, et al. two items indicators Shang reached significantly differences, description and traditional teaching compared, asynchronous teaching can effective development athletes speed, and power, and endurance, and sensitive, and coordination, et al. body capacity.

\subsubsection{Experiment classes and control classes to the mental health indicators and indicators of psychological stress}

Different teaching models will have an impact on the mental health of students, in order to explore the teaching on students psychological impact of asynchronous, based on the experimental class after class with CK SCL-90 scale evaluation of each factor were tested (results shown in table 4). Statistics show that semester classes and control classes students are forced, interpersonal sensitivity, anxiety, somatization, paranoia has a significant or very significant difference, et al. factor, total score and positive items, but also show significant differences, indicate that classes in experimental psychological level was significantly higher in the control group, and asynchronous teaching is more conducive to promoting the mental health of students. The reason is, this is due to the asynchronous teaching theory emphasizes the students ' main body position, asynchronous, the active participation of students and teachers to guide, to create a lively atmosphere in the classroom, students of different levels can experience the joy of movement. Good emotional experience in the sport will have a good influence on physical exercises behavior so as to realize the subjective efforts of physical exercise behavior. Students ' active learning, active, and have fun doing sports and exercise, which can improve mental health.

Because college students are facing social, family and school, et al. the environment is increasingly complex, with the increasingly fierce competition, so students in daily life, study, employment, economic and emotional, et al. psychological pressure increases, can produce anxiety, sadness, worry, depression, et al. emotion and psychological tension. From table 5, we see that, after a semester of asynchronous teaching and comparative indicators of psychological pressure of students in different dimensions, classes in healthy pressure of pressure, stress, low self-esteem, frustration, stress, relationship stress, stress, emotional strain, et al. 7 indicators on access to a significantly different or significantly different. Statistical test results indicate that asynchronous teaching can effectively help students overcome low self-esteem, improve relationships, increase their frustration resistance, which can effectively alleviate the pressures arising from health and academic pressures. Asynchronous teaching is superior to traditional learning of causes on is sports teaching in the with a levels of students Zhijian for mutual compared, can makes students of self-confidence and achievements sense greatly enhanced, they can active produced interactive, create happy of learning atmosphere, reduced its learning anxiety, in is big degree Shang reduce has students of thought pressure, improve has students learning of enthusiasm and active participation sex, makes its feel to success of happy, psychological pressure will gradually reduced. 
Table 5 different dimension classes and control classes students ' psychological pressure index of statistical tests

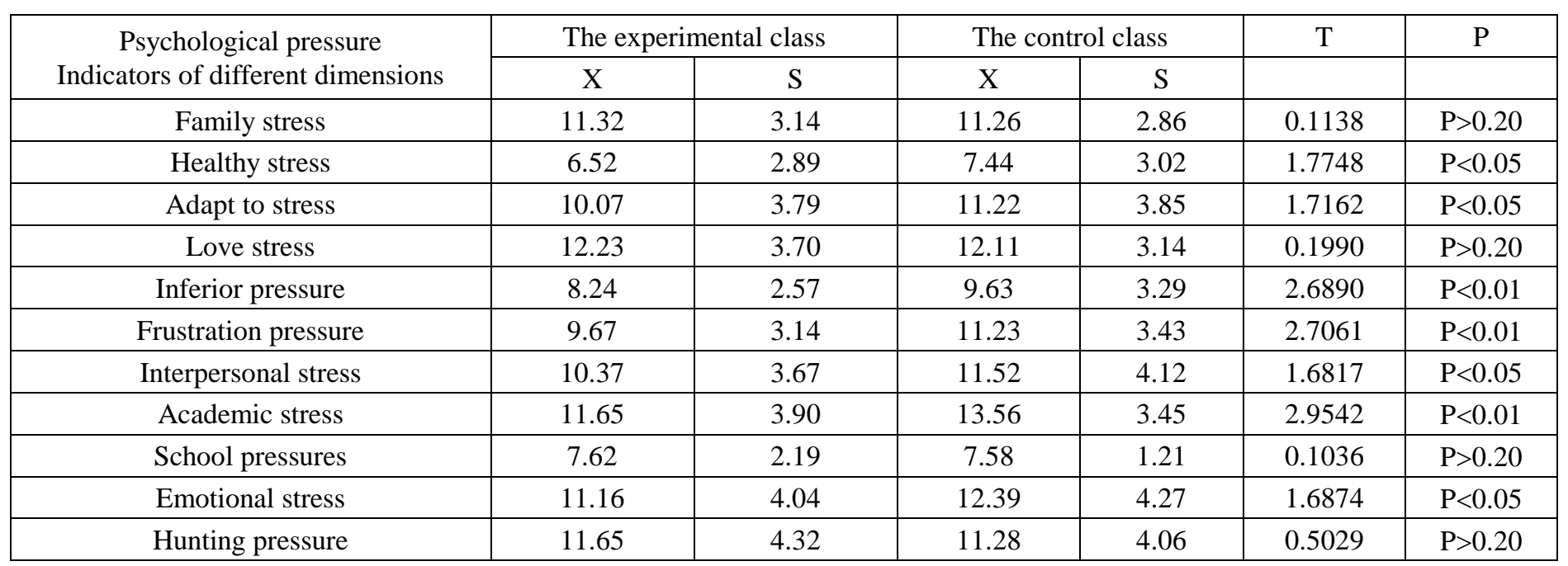

\section{CONCLUSIONS AND SUGGESTIONS}

1. Through experimental study on realization of the individualized learning of students in University physical fitness, improving class and instructor of an asynchronous, fully mobilize the enthusiasm of the students, not only improves the quality of teaching, but also to promote students ' physical and mental health.

2. Compared with traditional teaching methods and asynchronous teaching can effectively develop their speed, strength, stamina, agility, coordination of , et al. physical ability. Experiment class in the 100 meters, sit ups, step, sit and reach, 4x10-meter running up and down, et al. 5 indicators has a very significant difference. In the standing long jump and responses, et al. reached the significant differences in the two indicators.

3. Asynchronous teaching theory emphasizes the students ' principal role and individualized and therefore more conducive to promoting the mental health of students and ease the psychological pressure. Compared with the control group, students in anxiety, body, forced, interpersonal, paranoia has a significant or very significant difference, et al. factor in healthy pressure of pressure, stress, low self-esteem, frustration, pressure, social pressure, stress, emotional strain, et al. there was a significant or very significant differences in the index.

4. Asynchronous teaching is implemented, must proceed from actual conditions of students of physical education teachers, grouped in an objective manner. Grouped results will to a certain extent, affect the asynchronous teaching.
5. Physical education teachers need asynchronous teaching and organization and implementation of adequate preparations before each class, according to the characteristics of each group of students develop goals and plans, it is recommended that constantly sum up experience in teaching practice of physical education teachers in colleges and universities and actively participate in related skill training or experiencesharing sessions, further enhancing an asynchronous classroom teaching control ability.

\section{REFERENCES}

[1] Li Shifa. Asynchronous teaching theories and methods. Hubei: Xueyuan publishing house 1992.

[2] Ji Liu. Teaching theory of physical education and health course. Hangzhou: Zhejiang Education Publishing House, 2003.

[3] Zhang Liwei, Mao Zhixiong. Common psychological scale evaluation of sports science Handbook. Beijing: Beijing sport University Press 2004.

[4] Li Hongjiang. Cchool physical tutorial. Beijing: Beijing sport University Press, 2003.

[5] Chen Yanfei. Descending reason and countermeasures of the students study in China. Otsu, Journal of Institute of physical education, 2005 (4): 82-84.

[6] Zhang Lin, Wen Bo, Li Bing. Study on University students ' psychological stress coping. Psychological science, 2005, 28 (1): 36-41.

[7] Li Yubo, Comparison of synchronous teaching method of the asynchronous method and the traditional. Asynchronous teaching and research, 2002, (02): 25-26.

[8] Lei Jihong, et al.. Present situation and development trend of physical education teaching model in colleges and universities in China. Xian Institute of physical education journal, 2006 (3): 109-111.

[9] Xia Lun, Li Juchun. Asynchronous application of teaching method in swimming teaching. swim quarterly, 2005, (03): 19-22. 